\title{
Blended Learning Adoption in an ESL Context: Obstacles and Guidelines
}

William J. Shebansky

The integration of blended learning is well underway across diverse educational settings. Along with this shift in instructional method are obstacles and accompanying research. There has been less interest, however, in examining the adoption

of blended learning in English as a second language (ESL) contexts. This study investigates what factors most influence instructors to adopt blended learning in different ESL settings. This research is informed by the work of Porter, Graham, Bodily, and Sandberg (2015) in a university context. Utilizing the same frameworks in a mixed methods exploratory research design, I surveyed 48 ESL instructors from three different ESL settings, then followed up with interviews of nine Language Instruction for Newcomers to Canada (LINC) instructors. Quantitative data point to similarities in the factors that most influence the technology-adoption decisions of instructors across different ESL settings, primarily the ability to quickly upload and download materials and the availability of professional development. Qualitative data suggest that adoption is primarily hampered by required time commitments and the lack of technical supports. This research contributes to the discussion on blended learning adoption, specifically in relation to government-funded LINC programs. Lessons learned will facilitate instructor implementation and program policies.

L'intégration de l'apprentissage hybride avance bien dans bon nombre de milieux pédagogiques. Cette méthode pédagogique alternative s'accompagne d'obstacles et de recherches pertinentes. On s'est toutefois moins intéressé à l'examen de l'adoption de l'apprentissage hybride dans les contextes de l'apprentissage de l'anglais langue seconde (ALS). La présente étude examine les facteurs les plus susceptibles d'encourager les professeurs de langue à adopter l'apprentissage hybride dans divers milieux ALS. Cette recherche s'inspire des travaux de Porter, Graham, Bodily, et Sandberg (2015) dans un contexte universitaire. À l'aide des mêmes cadres à l'intérieur d'un plan de recherche exploratoire regroupant diverses méthodes, j'ai étudié 48 professeurs d'ALS auvrant dans trois milieux ALS différents, et j'ai ensuite réalisé des entrevues avec neuf professeurs de Cours de langues pour les immigrants au Canada (CLIC). Les données quantitatives font ressortir des ressemblances entre les facteurs ayant la plus grande influence sur les décisions prises par les professeurs de divers milieux ALS relativement à l'adoption des technologies, principalement la possibilité de téléverser et de télécharger rapidement le matériel et la disponibilité de perfectionnement professionnel. Les données qualitatives suggèrent que l'adoption est surtout entravée par l'importance du temps 
nécessaire et le manque de soutiens techniques. Cette recherche contribue à la discussion sur l'adoption de l'apprentissage hybride, particulièrement en rapport avec les CLIC financés par le gouvernement.

KEYWORDS: blended learning, instructor adoption, adoption factors, LINC and ESL contexts, implementation obstacles

The New Media Consortium (NMC) Horizon Report “2014 Higher Education Edition" describes the integration of online, blended, and collaborative learning as a fast trend driving changes in higher education (Johnson, Adams Becker, Estrada, \& Freeman, 2014). The same report also acknowledges the low digital fluency of faculty as a challenge to student learning: "Despite the widespread agreement on the importance of digital media literacy, training in the supporting skills and techniques is rare in teacher education and non-existent in the preparation of faculty" (p. 22). These findings are consistent with how teachers in Alberta perceive technology adoption in their high schools (Alberta Education, 2012). The report on technology and high school success in Alberta revealed that teacher professional development mainly focused on the basic functions of technology, and, "it is not always sufficient to allow teachers to effectively use technology in the classroom" (p. 46). The report added, however, that most of the surveyed teachers "would welcome additional professional development opportunities that were subject-specific and would help them to incorporate technology into their classrooms" (p. 46). English as a second language (ESL) contexts follow a similar pattern. In their study exploring the perceived challenges and benefits of e-learning in Ontario Adult Non-Credit ESL programs, Lawrence, Haque, King, \& Rajabi (2014) found that blended learning (BL) was, "strongly preferred as an ESL e-learning delivery option by administrators $(84 \%)$, instructors $(63 \%)$ and learners $(60 \%)^{\prime \prime}$ (p. 13) with training and support identified as a crucial element for the successful implementation of ESL e-learning. However, existing "oneshot professional development training models were recognized as clearly inadequate to address the dynamic and fast evolving nature of e-learning technologies and materials" (p. 16). There is no doubt that educators at all levels are increasingly exposed to digital technologies and expected to leverage them into their practice. Educators also seem to acknowledge the importance of these technologies for 21st century teaching and learning despite their deficiency in pertinent training.

As an ESL teacher, I see a variety of digital tools that are readily available and teacher accessible; however, I do not see teachers utilizing these tools to implement BL. This reluctance is supported by the literature, with Reid (2014) claiming, "although higher education has spent millions of dollars on instructional technologies, often higher education administration complains that instructors are not adopting them" (p. 383). In addition, professional 
development training does not always translate into uptake in practice. The Language Instruction for Newcomers to Canada (LINC) program at my workplace recently had a professional development opportunity to introduce a BL platform to interested instructors. Of the 20 instructors who attended the group presentation, only one pursued the technology with students. Even with the professional development opportunity and access to the learning platform, instructors did not embrace the new technology. This low uptake is disconcerting as instructors are not keeping pace with the integration of technology. They are also denying their students the different affordances offered by BL. Skills or components of language acquisition, learner autonomy, and digital literacy are among the most common affordances of technology for language learning (Godwin-Jones, 2016) and of crucial importance to succeed in today's world.

\section{Problem Statement}

Critical questions regarding barriers to technology emerged from the low adoption of BL at my workplace, which requires further exploration. An analysis and evaluation of these obstacles is needed so that they can be effectively addressed to encourage instructor implementation of BL. However, an extensive search of the literature yielded limited information on BL adoption in LINC contexts. This study aims to address this gap.

By gaining a deeper understanding of staff perceptions and identifying challenges that affect adoption, the implementation of BL can be expedited. This article asserts that instructors in LINC contexts lack the time and adequate supports to fully adopt BL. They tend to view BL positively, but use it minimally as opposed to exploiting its full potential. Therefore, this exploratory study investigated what institutional strategy, structure, and support factors most influence the technology adoption decisions of instructors in a LINC context, compared these factors across different ESL settings, and then derived suggestions for their improvement based on participant responses of why these factors facilitate or impede adoption.

\section{Research Questions}

I identified three questions to guide this research:

Research Question 1: Do participants in this study use BL? How does its use compare across different ESL settings?

Research Question 2: What institutional strategy, structure, and support factors most influence the adoption decision? How does this compare across different ESL settings?

Research Question 3: Why do certain institutional strategy, structure, and support decisions facilitate or impede BL adoption in a LINC context? 


\section{Definitions}

LINC is a language-training program funded by Immigration, Refugees and Citizenship Canada (IRCC) and provided free of charge to permanent residents. The program provides newcomers English-language skills to socially, culturally, and economically integrate into Canada (Hajer, Kaskens, \& Stasiak, 2007). This focus distinguishes LINC from private ESL programs that are normally offered at language schools, colleges, or universities. ESL programs are designed for specific disciplines, groups of learners, and specific skill levels. There are fees for private ESL programs, and they also tend to focus on international students and visitors to Canada. English-language programs in non-English-speaking regions or countries are typically called English as a foreign language (EFL). These programs may be part of the normal school curriculum or designed for learners' exam success and career progression. Although this study investigates BL adoption in LINC, ESL, and EFL programs, they are referred to more generally as different ESL settings for the purposes of this study. English-language instruction in different settings is the focus, not the distinction, of terms.

There are numerous models of $\mathrm{BL}$, which makes its definition somewhat ambiguous (Moskal, Dzuiban, \& Hartman, 2013). In fact, Moskal et al. (2013) conclude that, "blended learning has become an evolving, responsive and dynamic process that in many respects is organic, defying all attempts at universal definition" (p. 16). As definitions vary widely, a narrower definition is required. In this study, I adopt Garrison and Kanuka's description of BL as the thoughtful and intentional integration of face-to-face and online learning opportunities (Garrison \& Kanuka, 2004). Furthermore, this study focuses on the way net-based tools are used in the learning process rather than its implementation, such as replacement of classroom learning. There are also numerous net-based tools including online discussion forums, social media, video and audio tools, informational websites, online learning resources, and online quizzes, to name a few. Regardless of the tool used, this net-reliant definition of BL, "requires learners to access net-based tools at some point to successfully complete the learning transactions" (Kanuka \& Rourke, 2014, p. 22).

\section{Literature-Informed Discussion}

To help frame the current research, a brief overview of the opportunities and challenges that a BL approach presents as well as research-informed strategies to address possible shortcomings are provided. A description of the conceptual frameworks used in this study also follows.

\section{BL Opportunities}

Recently, there has been a lot of excitement about the opportunities that a blended approach to learning presents for students, faculty, and administration. Some of the opportunities identified in the literature include person- 
alization and pacing of learning (Jacobs, 2016), acquisition of 21st century learning skills (McLester, 2011), increased flexibility (Garnham \& Kaleta, 2002), more engaging and creative learning experiences (Ginns \& Ellis, 2007), lower withdrawal rates (Moskal, Dziuban, \& Hartman, 2013), and facilitated community of inquiry (Garrison \& Kanuka, 2004). Coll (2016) even reports increased student achievement by integrating out-of-school activities with classroom practices using digital technologies. Vaughan (2007) identified benefits from an administrative perspective, including enhanced reputation of an institution, expanded access to educational offerings, and reduced operating costs.

The LINC program incorporates such BL opportunities. The LearnIT2teach project (LearnIT2teach, 2017) provides LINC teachers with the technology tools and training to implement BL in their classrooms. In their evaluation report on BL innovation, Fahy, Sturm, McBride, and Edgar (2016) explain the LearnIT2teach project was recently mandated by IRCC, the funder of LINC, to "facilitate technology innovation in settlement language training" (p. 6) and to "reduce costs by using technologies to deliver training to both students and teachers" (p. 6). LINC instructors will be increasingly expected to interact with BL through student training or their own training.

\section{BL Challenges}

Many of the identified BL opportunities have associated challenges. One challenge is the lack of understanding about $\mathrm{BL}$, which can lead to confusion and frustration for students, teachers, and institutions (Oliver \& Trigwell, 2005). In addition, in their study exploring the adoption of BL practices in a business school at a U.K. university, Benson, Anderson, and Ooms (2011) note the perception of developing BL materials as time-consuming and of supporting technology as prone to failure. In particular, the authors claim, "barriers appeared to be related to the perception of developing the technology-based aspects of blended learning as time-consuming, including difficulties in locating relevant resources as so many are now available on the web" (p. 152). A similar perception was noted in an earlier study of Korean EFL teachers. Shin and Son (2007) concluded that although EFL teachers were positive toward the use of the Internet for teaching purposes, difficulties integrating Internet resources into curriculum, "seem to be caused by the huge amount of information available on the Internet and limited time to seek useful information" (p. 11). In their study examining the use of online teacher logs for responsive online teacher professional development (ROPD) programs, Riel, Lawless, and Brown (2016) also identified six themes of challenges that persisted for teachers during the implementation of a BL curriculum. Among the most frequently identified were "challenges in working with students on curriculum activities" (p. 180) and "challenges with curriculum orchestration" (p. 186), 
which was most often cited as the lack of time to do all activities. A host of challenges unquestionably exist.

\section{BL Strategies}

To address these types of shortcomings, Garrison and Kanuka (2004) suggest that "teaching faculty require assistance with course development needs, time management of their learning curve, and technical assistance" (p. 102). They also advise that the most effective support systems for teaching faculty "are those that provide a course development team for the development of blended learning courses" (p. 102). In other words, as Riel, Lawless, and Brown (2016) recognize, in order for BL to be successfully implemented, teacher's perspectives are valuable. The authors stress, "as teachers are the ultimate 'end users' of curricula, listening to their perspective during implementation is a critical function of ROPD design for today's blended classroom" (p. 192). Teachers also require pedagogical preparation. In his study, Jones (2001) focused on the role of the teacher in making technology an effective learning opportunity. For computer-assisted language learning (CALL) to succeed, teachers require, "technical training to anticipate the needs of computer novices" (para. 13) in addition to "training in the ability to deal sensitively with students" (para. 13) who lack interest in CALL or in its autonomous nature and required interactions. The internal and external influences affecting instructors' adoption of online tools (Brown, 2016) and a classification of factors promoting quality web-supported learning (Fresen, 2010) provide additional strategies to address the lack of BL adoption.

A recent model for successful technology implementation is showing promise. The Flexible Pathways project (Alberta Education, 2016) researched key factors that contribute to the implementation of educational technologies in Alberta classrooms. Model components include "implementation drivers, or 'building blocks,' needed to support school context, teacher and administrative practice, and systems change including leadership, teacher competencies, and organizational supports" (Alberta Education, 2016, p. 70). The project noted improvements in access to technology, increased infrastructure supports needed to integrate technology, development of teacher technology skills, and positive changes in teaching practices. Most notable, project participants "clearly saw the potential of technology to enhance their teaching practices and to better support all learners" (Alberta Education, 2016, p. 70). Improved lines of communication between implementation drivers and the willingness of leadership and staff to work together proved effective. The emerging model may serve as an effective strategy for technology implementation in ESL contexts. 


\section{Conceptual Frameworks}

I investigated the low technology adoption rate at my LINC workplace through two conceptual frameworks: Graham, Woodfield, and Harrison's (2013) institutional adoption and implementation of BL framework and Rogers's (2003) diffusion of innovations theory. Porter, Graham, Bodily, and Sandberg (2015) first implemented the two frameworks, and my research picks up where they left off, filling in an important gap.

The institutional adoption and implementation of BL framework identified three stages of BL development in institutions of higher education: Stage 1 is awareness/exploration, Stage 2 is adoption/early implementation, and Stage 3 is mature implementation/growth. The framework also identified three key markers or areas of consideration that universities may encounter across these three stages: strategy, structure, and support. Strategy includes design-related issues of BL. Structure includes issues surrounding facilitation of the BL environment. Support includes faculty implementation and maintenance of its BL design. This framework allowed Porter et al. (2015) to identify how strategy, structure, and support themes influenced faculty members' BL adoption decisions in their research.

The diffusion of innovations (DOI) framework explains how, why, and at what rate new ideas and technology spread. According to Rogers (2003), "diffusion is the process by which an innovation is communicated through certain channels over time among the members of a social system" (p. 5). He also added,

not all individuals in a social system adopt an innovation at the same time. Rather, they adopt in a time sequence, and they may be classified into adopter categories on the basis of when they first begin using a new idea. (p. 241)

The categories, based on the rate at which individuals adopt innovation, include innovators, early adopters, early majority, late majority, and laggards (Rogers, 2003). The DOI framework allowed Porter et al. (2015) to classify their research participants. In a similar way, the DOI was employed by Tshabalala, Ndeya-Ndereya, and van der Merwe (2014) to categorize academic staff in their faculty according to the rate of adoption of BL.

Using these classifications, Porter et al. (2015) investigated the extent to which the framework's institutional strategy, structure, and support decisions influence BL adoption, particularly among higher education faculty in the early majority and the late majority innovation adoption categories. I expanded on Porter et al.'s (2015) research by answering their call to conduct analogous surveys and interviews of part-time faculty regarding their rationales for BL adoption decisions. Doing so fills a void in the literature on BL adoption rates in LINC contexts. The two frameworks utilized by Porter et al. 
(2015) were used to inform and guide the research design and methodology of the current study to investigate the low BL adoption rate in a LINC context.

\section{Methodology}

\section{Research Design}

The convergent parallel mixed methods design (Creswell, 2014) best addresses this study's combination of research questions. A mixed methods design "combines quantitative and qualitative research techniques, methods, approaches, concepts or language into a single study" (Johnson \& Onwuegbuzie, 2004, p. 17) and was selected to provide a more thorough understanding of the research problem. Research Questions 1 and 2 of this study warrant a quantitative approach, whereas Research Question 3 a more qualitative perspective.

Both the quantitative and qualitative data were collected in parallel using the same concept, that is, the influence of institutional strategy, structure, and support factors. The data were also converged so that the perspectives of instructors were incorporated into the understanding of survey results. The design also asserts that the research question is most fundamental. Accordingly, "research methods should follow research questions in a way that offers the best chance to obtain useful answers" (Johnson and Onwuegbuzie, 2004, p. 17). Collecting, then integrating, quantitative and qualitative data in the interpretation of the results provided for a comprehensive analysis of the current research problem.

\section{Participants}

Participants included teachers and instructors in different ESL contexts: LINC instructors at an Edmonton LINC Service Provider Organization (SPO), ESL instructors at a midsized Canadian community college, and ESL instructors at a large Korean university. None of the individuals recruited was or presently is supervised by the researcher, and any practicing ESL teacher or instructor was welcome to participate.

The survey response rate was $51 \%$ for the LINC context, with 24 responses out of a population size of 47 instructors. The community college had a smaller population size of nine instructors, but $56 \%$ response rate with five respondents. The Korean university had a 39\% response rate with 19 out of 49 teachers responding. Overall, the response rate was $45 \%$ with 48 survey respondents out of 105 ESL teachers and instructors at three institutions.

Surveyed LINC instructors taught ESL ranging from less than 1 year to 29 years. On average, LINC instructors taught ESL for 9.1 years of which 4.4 years were at the current organization. Community college instructors taught ESL for an average of 15.8 years with 7.1 years at their current location. Likewise, the Korean university instructors taught ESL for an average 
of 16.9 years with 7.6 years at the same institution. All community college instructors and Korean university instructors indicated that they worked fulltime, whereas the majority of LINC instructors worked part-time. Only five out of the 24 LINC respondents worked full-time.

\section{Recruitment and Instrument}

I sent an e-mail requesting participation to the different ESL settings to obtain a stratified sampling of participants. An intermediary at the community college and Korean university forwarded my e-mail with the survey consent form and embedded survey collector link to fellow teachers and instructors at their ESL workplace. The consent forms explained potential use of these data and indicated that the research had been approved by a research ethics board. A four-part questionnaire (see Appendix A) was used to collect data from all participants. I adapted the questionnaire created by Porter et al. (2015), which determined the appropriate innovation adoption category for each faculty member and the factors that influenced faculty decisions to adopt BL. Permission to use the survey and interview protocol was granted by the original author. Some questions were slightly modified to better suit the participants and reflect the context of the current study (e.g., staff rather than faculty; and ESL as opposed to university level). In addition to demographic questions, the survey had participants indicate their use of select net-based tools, their typical reaction to new technologies, and the level of influence different factors would have on their adoption decision. The follow-up interview questions had participants express why the different factors would influence their decision to the level they indicated. Participants had a choice of questionnaire format: Survey Monkey (www.surveymonkey.com), an online survey tool, or an equivalent paper version. The paper version was used as an option to attract participants who may have been hesitant to answer a technologymediated questionnaire.

Both intermediaries were not in supervisory roles and were only contacted by participants who opted for the paper version of the survey. They assured confidentiality by ensuring participants not include any identifying information on collected paper surveys before sending them to me.

\section{Procedure}

I obtained quantitative data through participant surveys to provide numeric descriptions of BL trends, attitudes toward BL adoption, and the level of influence that institutional strategy, structure, and support decisions have on its adoption. Participants were free to discontinue participation at any time during the survey, and all submitted responses were anonymous. Responses from the survey were also not linked to interview responses. Clicking the "Done" button at the end of the survey submitted participant responses anonymously, so it was not possible to return or delete individual information at 
that point. Different survey collectors were used for the different ESL settings, but all were closed after 2 weeks. Participants spent an average of 9 min $31 \mathrm{~s}$ to complete the online survey. Given that Sax, Gilmartin, and Bryant (2003) identified highest response rates among students who received a paper survey with web option among four modes of survey administration, it is surprising that no participants opted for the paper version of the questionnaire.

I then sent a second recruitment e-mail with the interview consent form and actual interview questions (see Appendix B) to instructors at my place of employment only. The e-mail thanked all those who participated in the survey stage and invited them to participate in the follow-up qualitative interview stage. Nine LINC instructors participated. The one-on-one interviews involved approximately 20 min of participant time to answer 17 openended questions for feedback, thoughts, or opinions. The questions required responses as to why certain factors would influence participant decisions to the level indicated in their survey. Participants only received a blank copy of the survey questions to refresh their memory during the interview. All participants granted permission for the interviews to be digitally recorded, then transcribed.

No personal identifying information was collected in the interview, and confidentiality was protected through the use of participant-selected pseudonyms. Participants also had the opportunity to review the interview transcripts and remove any comments. Only I had access to the recordings, and the recordings were never played in public. I also transcribed all interview audio recordings myself. The audio files were destroyed within 2 weeks of completing the transcriptions, and the transcriptions will be destroyed 3 years after the completion of this study.

\section{Data Analysis}

After transcribing the interviews, I derived codes from the interview data through qualitative data analysis (Creswell, 2014). I analyzed these data for clusters of meaning, trends, and themes. The responses were divided into segments of information, then labeled with descriptive codes. Whenever possible, actual participant words were used for labeling. In order to be labeled, each segment of information had to answer the research question of "why" the particular response would facilitate or impede BL adoption. I coded the same interview question for all participants before moving on to the next question as they each target a possible factor that may facilitate or impede $\mathrm{BL}$ adoption. This helped maintain consistency in labeling. I compiled the frequency of descriptive codes for each factor. Groups of similar coding emerged, and I used significant statements and common themes to write a description of the reasons certain factors facilitate or impede BL adoption. I later triangulated these findings with the quantitative survey results across different ESL settings. Participant responses from the interview as to why 
certain institutional strategy, structure, and support decisions facilitate or impede BL adoption were compared with participant responses from a survey question on the greatest challenges experienced in placing a portion of their course online. This triangulation of data through different collection methods allowed me to analyze the research questions from multiple perspectives and contributed to a deeper understanding of instructor adoption decisions.

The validity of the research instrument and process during data analysis are important considerations. To achieve content validity, I included validated questions used from an existing survey (Porter et al., 2015) and engaged in some peer debriefing, primarily seeking feedback on format and process. Concurrent validity was also established by correlating ESL participant survey and interview results with Porter et al.'s (2015) results from a university context. As for reliability, it was imperative to ensure consistency in survey administration across the different ESL settings as well as in scoring. Sampling error was minimized by applying random sampling within each stratum.

\section{Findings}

After collecting and analyzing data from teacher surveys and interviews, I recorded and grouped the findings regarding participant use of BL, factors that most influence the adoption decision, and why the indicated factors facilitate or impede BL adoption. Prevailing perceptions of survey and interview respondents were also triangulated.

\section{Do Participants Use BL?}

The results from LINC teacher surveys are organized in Figure 1 based on respondents' reported adoption of various online technologies. In response to which online technology they provide in any of their classes, $82 \%$ of respondents $(n=14)$ selected other learning resources primarily used in class and made available online, such as handouts or PowerPoint presentations shown in class. A total of $59 \%$ of respondents $(n=10)$ also indicated that they used online learning resources primarily for online instruction, including videos, simulations, or websites. Participants in the LINC context use BL primarily with learning resources, which is similar to two other ESL contexts: the community college and the Korean university, as shown in Table 1. Eight participants of the 48 total survey respondents did not complete the survey question on the use of online technologies, resulting in a total sample of 40 respondents. The majority of Korean university respondents $(84 \%$, $n=16)$ and community college respondents $(50 \%, n=2)$ indicated their primary use of online technologies was for other learning resources used in class and made available online. The exception is for course outlines where $100 \%$ of respondents at the Korean university $(n=19)$ and $50 \%$ at the community college $(n=2)$ post their course outlines online. Posting of course outlines 
is mandatory for Korean university instructors, encouraged for community college instructors, but not required for LINC instructors.

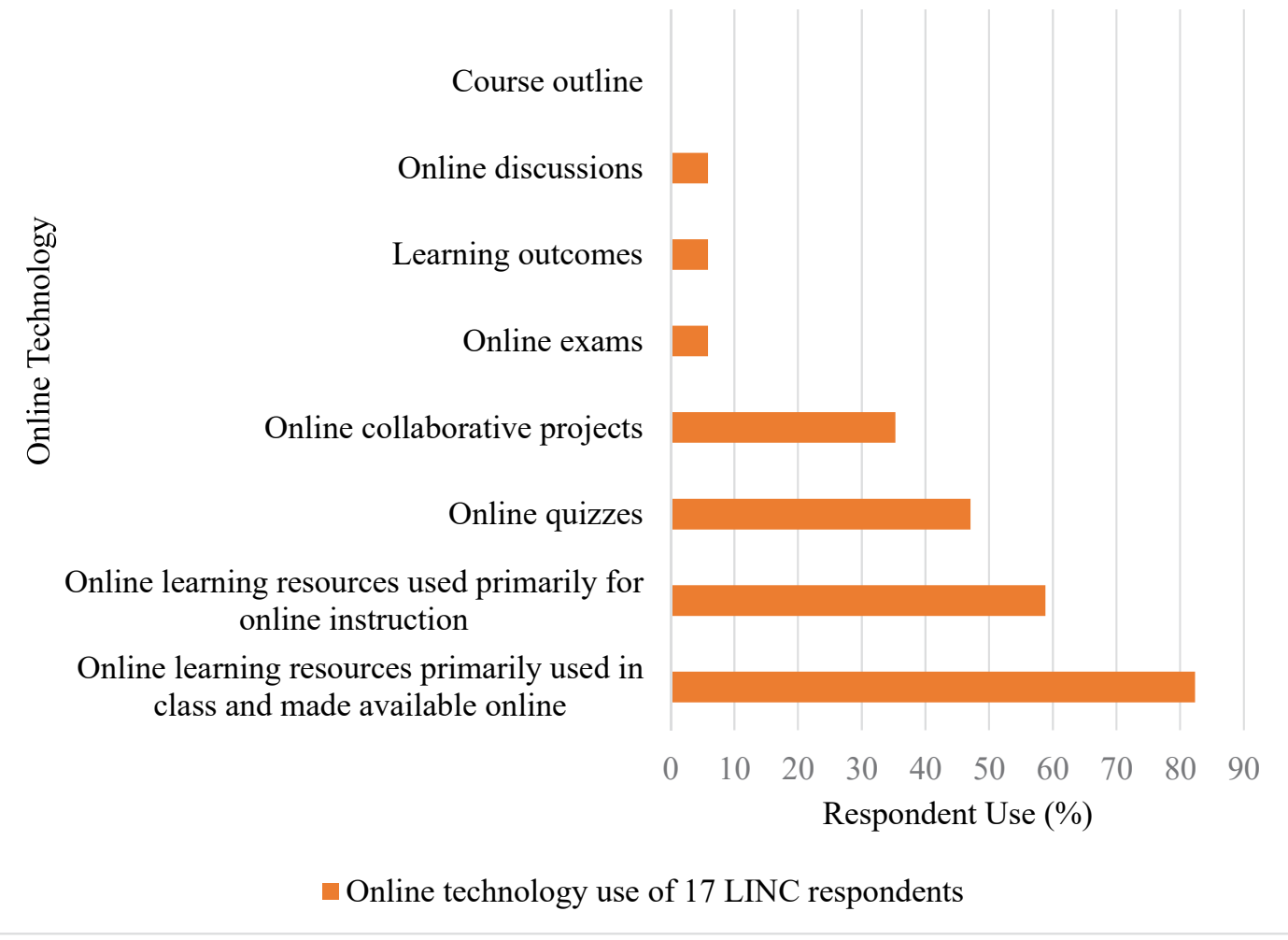

Figure 1: LINC respondent use of online technologies. The horizontal bars depict the percentage of respondents who use the indicated online technology. Results are based on 17 LINC respondents.

Note. LINC = Language Instruction for Newcomers to Canada.

Table 1

Participant Use of Online Technologies Across Three ESL Settings

\begin{tabular}{|c|c|c|c|c|}
\hline & & & Responses & \\
\hline Use of Online Technologies & Combined & LINC & Korean University & Community College \\
\hline $\begin{array}{l}\text { Other learning resources primarily used } \\
\text { in class and made available online }\end{array}$ & $80 \%$ & $82 \%$ & $84 \%$ & $50 \%$ \\
\hline $\begin{array}{l}\text { Online learning resources used primarily } \\
\text { for online instruction }\end{array}$ & $55 \%$ & $59 \%$ & $53 \%$ & $50 \%$ \\
\hline Online quizzes & $23 \%$ & $47 \%$ & $5 \%$ & $0 \%$ \\
\hline Online collaborative projects & $28 \%$ & $35 \%$ & $26 \%$ & $0 \%$ \\
\hline Online exams & $3 \%$ & $6 \%$ & $0 \%$ & $0 \%$ \\
\hline Learning outcomes & $18 \%$ & $6 \%$ & $32 \%$ & $0 \%$ \\
\hline Online discussions & $10 \%$ & $6 \%$ & $16 \%$ & $0 \%$ \\
\hline Course outline & $53 \%$ & $0 \%$ & $100 \%$ & $50 \%$ \\
\hline Live online class lecture & $0 \%$ & $0 \%$ & $0 \%$ & $0 \%$ \\
\hline Number of Respondents & 40 & 17 & 19 & 4 \\
\hline
\end{tabular}

Note. LINC = Language Instruction for Newcomers to Canada; ESL = English as a second language. 
Aside from the mandatory posting of course outlines, the majority of participants from all three ESL contexts tend to be cautious with technology adoption. Table 2 details participant reaction to innovation. The highest percentage of respondents from $\operatorname{LINC}(46 \%, n=11)$, the Korean university $(37 \%, n=7)$, and the community college $(80 \%, n=4)$ indicated that they wait to adopt until they have compelling evidence of the technology's value and recommendations from their peers.

Table 2

Participant Reaction to New Technologies Across Three ESL Settings

\begin{tabular}{|c|c|c|c|c|}
\hline Typical reaction to new technologies & Combined & LINC & $\begin{array}{l}\text { Korean } \\
\text { University }\end{array}$ & Community College \\
\hline $\begin{array}{l}\text { I am constantly adopting multiple new } \\
\text { technologies. }\end{array}$ & $4 \%$ & $8 \%$ & $0 \%$ & $0 \%$ \\
\hline $\begin{array}{l}\text { I actively investigate new technologies and } \\
\text { adopt the best ones. }\end{array}$ & $21 \%$ & $21 \%$ & $26 \%$ & $0 \%$ \\
\hline $\begin{array}{l}\text { I wait to adopt until I have compelling } \\
\text { evidence of the technology's value and } \\
\text { recommendations from my peers. }\end{array}$ & $46 \%$ & $46 \%$ & $37 \%$ & $80 \%$ \\
\hline $\begin{array}{l}\text { I am cautious and will only adopt when it } \\
\text { becomes necessary to do so. }\end{array}$ & $27 \%$ & $25 \%$ & $32 \%$ & $20 \%$ \\
\hline $\begin{array}{l}\text { I will continue using my current resources, } \\
\text { even when pressured to adopt a new } \\
\text { technology. }\end{array}$ & $2 \%$ & $0 \%$ & $5 \%$ & $0 \%$ \\
\hline Number of Respondents & 48 & 24 & 19 & 5 \\
\hline
\end{tabular}

Note. LINC = Language Instruction for Newcomers to Canada; ESL = English as a second language .

The second most common reaction for all three ESL contexts was respondents are not necessarily opposed to new technologies. In total, $25 \%$ of LINC respondents $(n=6), 32 \%$ of Korean university respondents $(n=6)$, and $20 \%$ of community college respondents $(n=1)$ indicated they are cautious and will only adopt when it becomes necessary to do so. These two groupings represent the Early Majority (EM) and Late Majority (LM) categories in Rogers's (2003) diffusion of innovations framework and the target interviewees in Porter et al.'s (2015) research on BL adoption. As early adopters take initiative on their own and laggards resist new innovations overall, Porter et al. (2015) focused on the EM and the LM, reasoning that the purpose of their study was "to provide institutional administrators and others interested in BL adoption with information regarding how to facilitate adoption among their faculty" (p. 19). The same can be said of the current study. The majority of participants across all three ESL settings fall within the EM and LM categories and, thus, serve a "pivotal role in institutional BL adoption" (Porter et al., 2015, p. 17).

In addition to being EM and LM, participants in this study also viewed BL favorably. When asked for their reaction to placing a portion of their course online, the majority of all three ESL contexts responded positively or positively with a condition, as indicated in Table 3 . Three of the 48 total survey respondents did not complete the survey question, resulting in a total 
sample of 45 respondents. In all, $40 \%$ of respondents $(n=18)$ were positive as long as some conditions were in place. Typical responses were dependent on whether additional time or wages were given to do it, proper guidance and supports were available, or if significant training or professional development were offered. This favorable attitude is encouraging for administrators of ESL programs attempting to facilitate BL adoption.

Table 3

Participant Reaction to Placing a Portion of Their Course Online

\begin{tabular}{lllll}
\hline & & \multicolumn{3}{c}{ Responses } \\
Reaction & Combined & LINC & $\begin{array}{l}\text { Korean } \\
\text { University }\end{array}$ & $\begin{array}{l}\text { Community } \\
\text { College }\end{array}$ \\
Positive & $31 \%$ & $36 \%$ & $26 \%$ & $25 \%$ \\
Positive with condition & $40 \%$ & $36 \%$ & $47 \%$ & $25 \%$ \\
Negative & $27 \%$ & $23 \%$ & $26 \%$ & $50 \%$ \\
Neutral & $2 \%$ & $5 \%$ & $0 \%$ & $0 \%$ \\
Number of Respondents & 45 & 22 & 19 & 4 \\
\hline
\end{tabular}

Note. LINC = Language Instruction for Newcomers to Canada.

What Factors Most Influence the Adoption Decision?

The results from participant surveys are organized in Figure 2 based on respondents' selection of factors that significantly influence their adoption decision. The factors that most influence the adoption decision include the ability to quickly upload and download media/materials at the workplace $(64 \%$ of LINC instructors $[n=14])$ and the availability of professional development or training in a face-to-face group setting for those placing a portion of their course online (55\% of the same respondents [ $n=12]$ ). This aligns closely to the other ESL contexts. When averaged, the ability to quickly upload and download media/materials at the workplace was selected as significant for $51 \%$ of all respondents $(n=23)$ and whether the institution's reason for promoting technology integration aligns with their own for $42 \%(n=19)$. The availability of professional development/training presented in a face-to-face group setting $(38 \%, n=17)$ and the availability of technical support $(38 \%, n=$ 17) for those placing a portion of their course online also had a significant influence across all ESL settings. Aside from the community college indicating that evaluation data on the effectiveness of placing a portion of a course online had a significant influence $(75 \%, n=3)$, all three ESL contexts selected the same top six factors that significantly influence their adoption decision.

\section{Why Do Certain Factors Facilitate or Impede BL Adoption?}

I ascertained why identified factors would influence the adoption decision in a LINC context through qualitative coding and analysis of participant in- 
terviews. I compiled the frequency of descriptive codes for each factor. A total of 286 codes were derived from these data through conventional content analysis. However, discussion surrounding the reasons will focus on the most significant factors influencing adoption decisions as identified in the LINC context of Figure 2. Doing so best addresses the needs of the current LINC context and aim of this study, but can be extrapolated to other ESL contexts analyzed through this research.

Ability to quickly upload and download media/materials. By far, the most frequent and probably expected coded theme for the ability to quickly upload and download media or materials was time, both time needed for instructor as well as student. Another reason was it affects implementation. Slow uploads and downloads are frustrating and may deter use and implementation of BL. Participant R explains,

if we're doing it in class and the labs, if you're faced with a lot of obstacles where if the Wi-Fi not working or certain equipment not working, or, umm, roadblocks in that way, it's gonna' create more hassle than convenience.

Availability of professional development/training in face-to-face group settings. Instructors felt that professional development or training in faceto-face group settings were beneficial in that collaboration and learning were fostered through the sharing of ideas. Collaboration can also give instructors an idea of the possibilities, and so it is inspirational. However, the findings suggest that one-on-one training is preferable as participant skills and needs vary in group settings, which may ultimately be distracting and waste time. As Participant B explains, "if too many people are asking questions, everyone has different needs ... you still have someone there, but you're going to get distracted."

Availability of one-on-one professional development/training. In providing the reason why the availability of one-on-one professional development would be an influence, instructors listed a variety of benefits to their learning, including immediate personalized support, guidance, and questions answered in a time-efficient manner as well as longer term gains through improved implementation, more creative activities, student benefit, and career satisfaction. Overall, the response to one-on-one professional development or training was unanimously positive and the preferred training mode. As Participant B states, "if you had one-on-one professional training, someone to guide you through the steps, I do think that, umm, is more likelihood that I might take it on." 


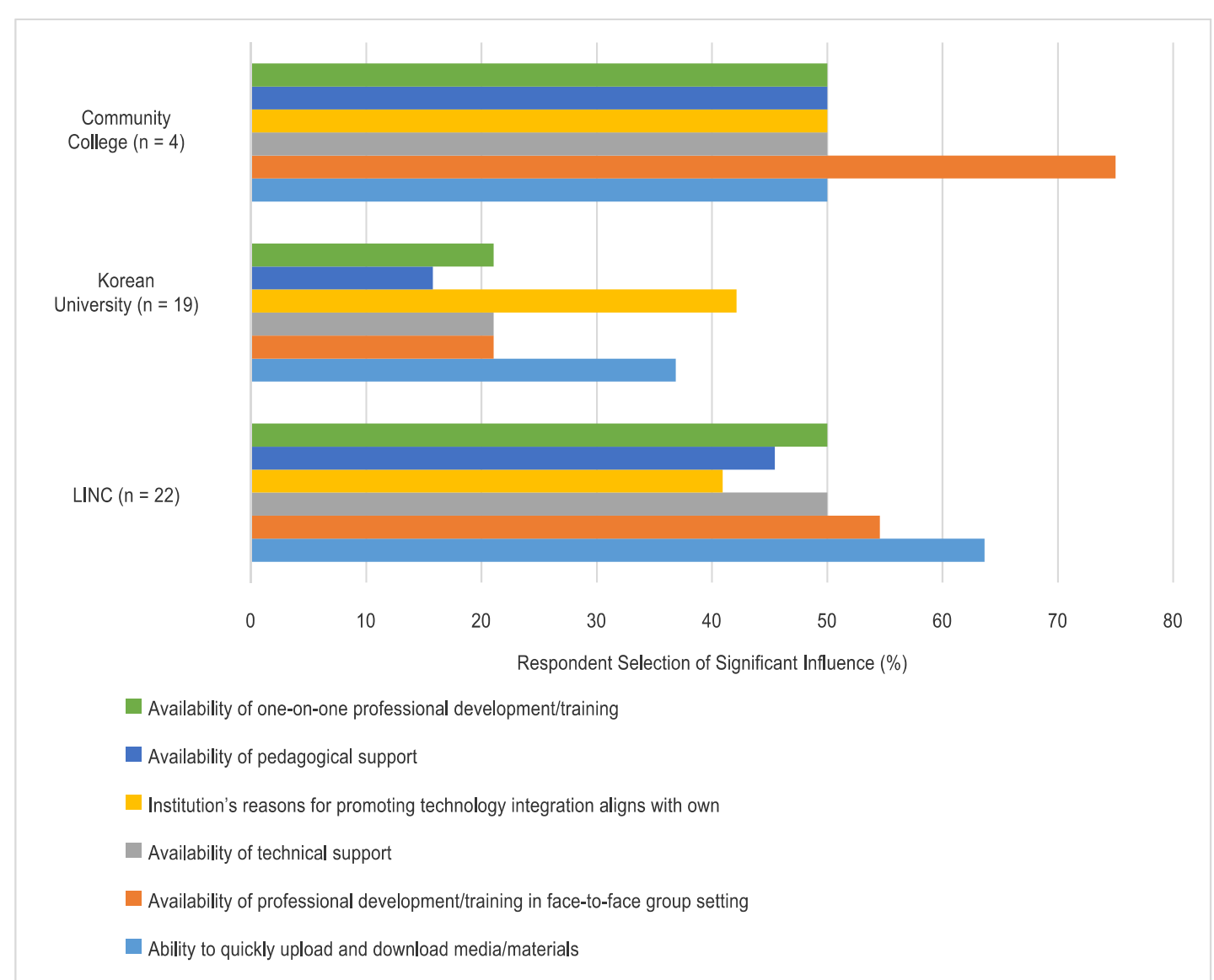

Figure 2. Key factors influencing BL adoption decision. The horizontal bars are grouped into ESL contexts and depict the percentage of respondents who selected the indicated factor as having a significant influence on their BL adoption decision. Results are based on 45 total respondents.

Note. BL = blended learning; ESL = English as a second language.

Availability of technical support. The availability of technical support was another significant factor influencing technology-adoption decisions. Respondents indicated that technical difficulties, such as network performance or computer glitches, are prevalent, and they need extra help to address them as they lack the technical skills. Participant $Z$ explained, "I'm not very techy, so any support [laugh] that would be offered, you know that would, that would change me trying this, quite a bit." Providing technical support encourages use, instills confidence, and minimizes frustration. As described by Maggie, "It gets frustrating when you can't, uhm, do something because the system has crashed, and, uhm, especially if there's no technical support available to help you, uhm, resolve those issues."

Availability of pedagogical support. Although not as significant a factor as technical support, respondents indicated that the availability of pedagogical support is efficient as it reduces time needed for research or preparation. "They could really teach you a lot in a relatively short amount of time. Uhm, like they'd have in hand all those things that I don't find very in- 
teresting," states John. However, it is a future need as other supports should be addressed first, such as the lack of funds, expertise, or tech problems. Participant $Z$ responded, "I just can't really imagine that situation occurring, umm, in the kind of institution that I work at. I don't think the funds are available for that kind of thing or even the expertise, umm, so that would have a little bit less influence."

Institution and individual reasons for promoting technology align. Instructors indicated that it is important that the institution's reasons for promoting technology align with their own. They described this relationship like "money in the bag" (John), "a slam dunk" (ER), and "like a hand and glove, it just fits" (Catherine). Instructors also need to understand the value and reason for promoting technology. This was indicated in seven instances. They have to understand the necessity and connection. As Catherine responded, "Once I understand the reason for it, then I will advocate the, the use of it." Maggie raised another point when stating, "it's absolutely important that they're on board with what you're doing, uhm, because there's a lot of resistance when you're, uh, trying something without your institutional, your institution's backing." Not only should the institution's reasons align with instructors' motivations for promoting technology, it should also support and back attempts to do so.

Prevailing Perception. In addition to analyzing the individual factors that influence adoption decisions, I evaluated participants' prevailing perceptions to establish a big picture summary. Table 4 displays the six most frequent instances of in vivo coding from all nine respondents. The frequency of themes implies importance, and, thus, a general reason. The main reasons why certain institutional strategy, structure, and support decisions facilitate or impede BL adoption in a LINC context include the need for a significant time commitment from teachers and the necessity of support, primarily personalized technical training and professional development. Technology issues and financial incentives are also important as are workload concerns that come with learning new skills.

Table 4

Frequency of Themed Interview Codes $(N=9)$

\begin{tabular}{ll}
\hline Theme & Frequency \\
Support (technical, time, personalized, guidance, training, PD) & 38 \\
Time (commitment, convenience, student) & 37 \\
Technology (problems, comfort, access, usefulness) & 20 \\
Financial (incentive, reward, compensation, lack funds) & 19 \\
Workload (heavy, increase) & 11 \\
Skills (lack, new, keep up) & 10 \\
\hline
\end{tabular}

Note. $\mathrm{PD}=$ professional development. 
These findings are consistent with participant survey results. Participants from all three ESL contexts responded to the greatest challenges they experienced or anticipate experiencing in placing a portion of their course online. I coded, then categorized, the survey results into the most frequent themes, or challenges. Table 5 compares the frequency of interview coded themes, or reasons, with the frequency of survey coded themes, or greatest challenges. Not only were support, time, and technology the three most frequent reasons that facilitate or impede BL adoption from the interview data, they were consistently the top three challenges indicated in these survey data across all ESL contexts. The one exception is the LINC context where lack of skills was identified as a greater challenge than support.

Table 5

Frequency of Factors Inhibiting BL Adoption

\begin{tabular}{|c|c|c|c|c|}
\hline \multirow[b]{2}{*}{ Theme } & \multicolumn{4}{|c|}{ Survey (greatest challenges) } \\
\hline & Interview & LINC & $\begin{array}{l}\text { Korean } \\
\text { University }\end{array}$ & $\begin{array}{l}\text { Community } \\
\text { College }\end{array}$ \\
\hline $\begin{array}{l}\text { Support (technical, time, personalized, guidance, } \\
\text { training, PD) }\end{array}$ & 38 & 3 & 8 & 4 \\
\hline Time (commitment, convenience, student) & 37 & 7 & 2 & 3 \\
\hline Technology (problems, comfort, access, usefulness) & 20 & 7 & 10 & 2 \\
\hline Financial (incentive, reward, compensation, lack funds) & 19 & 0 & 0 & 0 \\
\hline Workload (heavy, increase) & 11 & 1 & 1 & 1 \\
\hline Skills (lack, new, keep up) & 10 & 11 & 0 & 0 \\
\hline Total Identified Codes & 286 & 36 & 29 & 12 \\
\hline
\end{tabular}

Note. $\mathrm{BL}=$ blended learning; $\mathrm{LINC}=$ Language Instruction for Newcomers to Canada; $\mathrm{PD}=$ professional development.

\section{Discussion}

This study extended Porter et al.'s (2015) research on BL adoption in higher education to a part-time LINC context. A convergent parallel mixed methods design proved effective in discovering what factors most influence technology-adoption decisions through an analysis of quantitative results, while qualitative findings explained why those factors influenced participants' decisions to the level indicated. The results point to the usefulness of understanding institutional strategy, structure, and support factors and their influence on technology adoption. The findings from this study indicate that instructors in LINC contexts lack the required supports, time, and technology to fully adopt BL. They tend to be positive of BL, but use it primarily with learning resources, similar to other ESL contexts.

The current study findings are consistent with previous studies. The importance of support and time align with Porter et al.'s (2015) research in that more than two thirds of their respondents indicated, "course load reductions would be influential because they needed time in order to adopt BL, they 
needed time for other matters, they needed more time in general, or time is important" (p. 24). Benson et al. (2011) point out that the "availability of resources such as time, technology and support of e-developers also surfaced as determinants of positive attitudes towards adopting new teaching practices" (p. 153). Within language-teaching contexts, Shin and Son (2007) emphasize the importance of support and technology in their study of Korean EFL teachers' perceptions on Internet-assisted language teaching (IALT). In particular, "teachers need appropriate computer facilities with reliable Internet connections as well as technical support to implement and promote IALT, which can improve the teaching of EFL" (p. 11). Furthermore, Lawrence et al.'s (2014) study of e-learning in Ontario ESL programs discovered that inadequate e-learning infrastructure was cited as a barrier to ESL e-learning by "77\% of instructors, $70 \%$ of administrators and over half of the learners" (p. 14) and the lack of tech support as "a significant barrier for $77 \%$ of administrators and $61 \%$ of instructors" (p. 15). These values closely mirror the LINC findings of this study and illustrate that required supports, time, and technology are critical factors when choosing to implement BL for instructors across different ESL contexts, as they are for academic staff at higher education.

The results have implications for both instructors and program administrators. LINC instructors can realize that the challenges they face are not unique to their context. English instructors in different educational settings and country also feel that the ability to quickly upload or download materials and the availability of professional development and training are the biggest obstacles to embracing BL. Knowing this can help LINC instructors prioritize their professional development opportunities through specific technical training requests or individual engagement. In their study, Abbott, Rossiter, and Hatami (2015) offer a convincing argument on the benefits of instructors engaging with peer-reviewed research articles. Participating instructors "believed their reading of quality research articles had an impact on their practice" (p. 96). By extension, engaging with quality technology or BL research articles should have an impact on its implementation. They recommend, however, that this should also include the collaboration and support of professional associations, funders, and administrators.

Awareness of the barriers to technology in enhancing teaching also has implications for instructor training and pedagogy. The study reveals that instructors use online technologies predominantly as learning resources, such as handouts and PowerPoint presentations or for online instruction including videos and websites. LINC instructors are using tech-enhanced approaches, but minimally in their practices. This hesitation suggests instructors require pedagogical preparation in order to be competent enough to use technology to create an environment in which learners excel from the different affordances offered by BL. Pedagogical instructor training could, for example, "prepare teachers for their new roles to use technology for collaboration and engagement" (Riasati, Allahyar, \& Tan, 2012, p. 27). An interesting finding 
was that surveyed LINC instructors indicated that lack of skills was a greater challenge than support in comparison to the other ESL contexts. This may be interpreted as LINC instructors feeling that even if they are provided muchneeded supports, their technology fluency, or lack thereof, is the greatest challenge to the implementation of BL. A mind shift is also clearly needed for transition from traditional pedagogy to technology-enriched instruction.

The role of program administrators in their collaboration and support of instructors is critical. The Flexible Pathways project (Alberta Education, 2016) demonstrated that improved communication and cooperation between leadership and staff lead to successful technology implementation. The current study pinpoints obstacles to BL adoption and why it influences instructors' decisions. If LINC programs are serious about expanding BL options, it might be worthwhile to move beyond consideration and act on this study's findings. Providing a job-embedded, ongoing, mentorship model of professional development (Lawrence et al., 2014, p. 16) with relevant technical training and support, recognizing time commitment through financial compensation, and resolving technology problems promptly is a good start and will encourage instructor buy-in. In addition, when choosing to introduce new educational technologies, administrators should be mindful that they "lessen the workload of the instructors by reducing administrative tasks" (Mirriahi, Vaid, \& Burns, 2015, p. 9). LINC instructors have identified their needs. By addressing these needs, program administrators are expressing a desire to collaborate and support instructors. Doing so will go far in enhancing BL adoption in a LINC context. Doing so achieves IRCC's goal of facilitating technology innovation in settlement language training. Doing so realizes 21st century teaching and learning.

\section{Limitations, Future Research, and Conclusions}

The research reported in this article cannot be generalized to all online BL programs in all ESL educational contexts. With regard to participants, I purposely selected the different educational contexts based on my association with the organization. I have contacts at the different ESL settings who were willing to assist with the data collection. This made it difficult to know if the results are representative across similar "non-solicited" educational contexts. Another limitation of this study is related to its context. The study was conducted at a nonprofit agency that offers LINC English classes as well as various career and settlement services. English classes are offered face-to-face and utilization of BL is optional. The findings of this study may be different from those found in other ESL contexts that have mandated the use of BL or offer courses in a blended format. Future research could be extended to such contexts or on pedagogical approaches for technology-enriched LINC instruction and community-based ESL. Furthermore, BL applications are not only used in ESL contexts, but also in corporate and governmental in-service 
training contexts. Because the definitions and opinions of educational staff in relation to BL could be different from trainers working in a corporate culture, the findings of this study may not be generalized beyond education settings.

Even considering these limitations, the findings add significant value to our understanding of BL adoption in ESL and provide several important implications for both instructors and program administrators to expedite this increasingly popular teaching method.

\section{Acknowledgements}

This article reports findings from my MEd research project. Sincere appreciation to Dr. Michele Jacobsen for her guidance and support as my academic supervisor; the anonymous reviewers and editor for their helpful suggestions; and all the project participants for their generosity in taking the time to be involved in the study. Special acknowledgement goes to Dr. Wendy Porter for granting permission to use the survey and interview protocol of her team's published research.

\section{The Author}

William Shebansky is an Edmonton-based instructor. His interests include TESL and eLearning instructional design. He is a graduate of the MEd Interdisciplinary Research program at the University of Calgary.

\section{References}

Abbott, M., Rossiter, M., \& Hatami, S. (2015). Promoting engagement with peer-reviewed journal articles in adult ESL programs. TESL Canada Journal, 33(1), 80-105. doi:10.18806/tesl. v33i1.1228

Alberta Education. (2012). Technology and High School Success (THSS) final report. Retrieved from http://education.alberta.ca/media/6807230/technology\%20and\%20high\%20school\%20 success \%20final\%20report.pdf

Alberta Education. (2016). Flexible pathways to success: Technology to design for diversity. Retrieved from https://education.alberta.ca/media/3272631/uofa-flexible-pathways_finalreport_july26-2016_online.pdf

Benson, V., Anderson, D., \& Ooms, A. (2011). Educators' perceptions, attitudes and practices: Blended learning in business and management education. Research in Learning Technology, 19(2), 143-154. doi:10.1080/21567069.2011.586676

Brown, M. G. (2016). Blended instructional practice: A review of the empirical literature on instructors' adoption and use of online tools in face-to-face teaching. The Internet and Higher Education, 31(1), 1-10. doi:10.1016/j.iheduc.2016.05.001

Coll, S. (2016). Pedagogy for education on sustainability: Integrating digital technologies and learning experiences outside school. Eco-thinking, 1(1). Retrieved from http://eco-thinking. org/index.php/journal/article/view/11/19

Creswell, J. W. (2014). Research design: Qualitative, quantitative, and mixed methods approaches (4th ed.). Thousand Oaks, CA: SAGE Publications, Inc.

Fahy, P., Sturm, M., McBride, R., \& Edgar, J. (2016). Narrative and evaluation report: Blended learning innovation for IRCC settlement language training. Retrieved from http://learnit2teach.ca/ wpnew/wp-content/uploads/LearnIT2teach_13_16_Eval_Rpt.pdf

Fresen, J. W. (2010). Factors influencing lecturer uptake of e-learning. Teaching English with technology, Special Edition on LAMS and learning design, 10(3), 81-97. Retrieved from http:// 
yadda.icm.edu.pl/yadda/element/bwmeta1.element.desklight-8ab4ac01-98db-4246-aa73eeb091043d06/c/6fresen.pdf

Garnham, C., \& Kaleta, R. (2002). Introduction to hybrid courses. Teaching with Technology Today, 8(6). Retrieved from http://www.uwsa.edu/ttt/articles/garnham.htm

Garrison, D.R., \& Kanuka, H. (2004). Blended learning: Uncovering its transformative potential in higher education. The Internet and Higher Education, 7(2), 95-105. doi:10.1016/j.iheduc.2004.02.001

Ginns, P., \& Ellis, P. (2007). Quality in blended learning: Exploring the relationships between on-line and face-to-face teaching and learning. Internet and Higher Education, 10(1), 53-64. doi:10.1016/j.iheduc.2006.10.003

Godwin-Jones, R. (2016). Looking back and ahead: 20 years of technologies for language learning. Language Learning \& Technology, 20(2), 5-12. Retrieved from http://lt.msu.edu/issues/ june2016/emerging.pdf

Graham, C. R., Woodfield, W., \& Harrison, J. B. (2013). A framework for institutional adoption and implementation of blended learning in higher education. The Internet and Higher Education, 18(1), 4-14. doi:10.1016/j.iheduc.2012.09.003

Hajer, A., Kaskens, A., \& Stasiak, M. (2007). LINC 5-7 curriculum guidelines: Language instruction for newcomers to Canada. Toronto, Ontario, Canada: Toronto Catholic District School Board. Retrieved from http://atwork.settlement.org/downloads/linc/LINC_Curriculum_Guidelines_5-7.pdf

Jacobs, J. (2016). High school of the future: Cutting-edge model capitalizes on blended learning to take personalization further. Education Next, 16(3), 44+.

Johnson, L., Adams Becker, S., Estrada, V., \& Freeman, A. (2014). NMC Horizon Report: 2014 Higher Education Edition. Austin, Texas: The New Media Consortium. Retrieved from http:// www.nmc.org/publications/2014-horizon-report-higher-ed

Johnson, R., \& Onwuegbuzie, A. (2004). Mixed methods research: A research paradigm whose time has come. Educational Researcher, 33(7), 14-26. doi:10.3102/0013189X033007014

Jones, J. (2001). CALL and the teacher's role in promoting learner autonomy [Electronic Version]. CALL-EJ Online, 3(1). Retrieved from http://callej.org/journal/3-1/jones.html

Kanuka, H., \& Rourke, L. (2014). Using blended learning strategies to address teaching development needs: How does Canada compare? Canadian Journal of Higher Education, 43(3), 19-35.

Lawrence, G., Haque, E., King, J., \& Rajabi, S. (2014). Exploring the feasibility of e-learning in Ontario ESL programs. Contact, 40(1), 12-18. Retrieved from http://www.teslontario.org/ uploads/publications/contact/ContactSpring2014.pdf

LearnIT2teach (2017, March 27). Teacher training. Retrieved from http://learnit2teach.ca/wpnew/ about-2/professional-development/

Mirriahi, N., Vaid, B. S., \& Burns, D. P. (2015). Meeting the challenge of providing flexible learning opportunities: Considerations for technology adoption amongst academic staff. Canadian Journal of Learning and Technology, 41(1). Retrieved from http://www.cjlt.ca/index.php/cjlt/ article/view/863

McLester, S. (2011). Building a blended learning program: Combining face-to-face and virtual instruction addresses all learners in the pursuit of 21st century skills. District Administration, 47(9). Retrieved from https://www.districtadministration.com/article/building-blendedlearning-program

Moskal, P. D., Dziuban, C. D., \& Hartman, J. (2013). Blended learning: A dangerous idea? Internet and Higher Education, 18(1), 15-23. doi:10.1016/j.iheduc.2012.12.001

Oliver, M., \& Trigwell, K. (2005). Can blended learning be redeemed? E-Learning and Digital Media, 2(1), 17-26. doi:10.2304/elea.2005.2.1.17

Porter, W., Graham, C., Bodily, R. \& Sandberg, D. (2015). A qualitative analysis of institutional drivers and barriers to blended learning adoption in higher education. The Internet and Higher Education, 28(1), 17-27. doi:10.1016/j.iheduc.2015.08.003 
Reid, P. (2014). Categories for barriers to adoption of instructional technologies. Education and Information Technologies, 19(2), 383-407. doi.org/10.1007/s10639-012-9222-z

Riasati, M. J., Allahyar, N., \& Tan, K-E. (2012). Technology in language education: Benefits and barriers. Journal of Education and Practice, 3(5), 25-30. Retrieved from http://iiste.org/Journals/ index.php/JEP/article/view/1495/1427

Riel, J., Lawless, K. A., \& Brown, S. W. (2016). Listening to the teachers: Using weekly online teacher logs for ROPD to identify teachers' persistent challenges when implementing a blended learning curriculum. Journal of Online Learning Research, 2(2), 169-200. Retrieved from https://papers.ssrn.com/sol3/papers.cfm?abstract_id=2820338

Rogers, E. M. (2003). Diffusion of innovations. New York: The Free Press. Retrieved from https:// teddykw2.files.wordpress.com/2012/07/everett-m-rogers-diffusion-of-innovations.pdf

Sax, L. J., Gilmartin, S. K., \& Bryant, A. N. (2003). Assessing response rates and nonresponse bias in web and paper surveys. Research in Higher Education, 44(4), 409-432. doi:10.1023/A:1024232915870

Shin, H.-J., \& Son, J.-B. (2007). EFL teachers' perceptions and perspectives on Internet-assisted language teaching. CALL-EJ Online, 8(2). Retrieved from https://eprints.usq.edu.au/1924/1/ Shin_Son.pdf

Tshabalala, M., Ndeya-Ndereya, C., \& van der Merwe, T. (2014). Implementing blended learning at a developing university: Obstacles in the way. The Electronic Journal of e-Learning, 12(1), 101-110.

Vaughan, N. D. (2007). Perspectives on blended learning in higher education. International Journal on E-Learning, 6(1), 81-94. Retrieved from http://www.thefreelibrary.com/Perspectives+on+b lended+learning+in+higher+education-a0159594390

\section{Appendix A. Survey}

\section{A.1. Demographics}

1. How many years have you taught ESL? [Allows for 1 decimal place]

2. How many years have you taught at your institution?

3. What year were you born?

4. Which of the following BEST describes your current status at the organization?

a. Full-time instructor

b. Part-time instructor

c. Other

5. Do you teach any fully online courses?

\section{A.2. Identify Category of Innovation Adopter}

Please answer the following questions for your institution courses only (not your fully online courses).

1. Please indicate which of the following you provide online for ANY of your classes (excluding fully online classes)? [option to select yes/no for each-follow-up/indented questions given following "yes" responses]

a. Course outline

b. Other learning resources primarily used in class and made available online (e.g., PowerPoint presentations shown in class, handouts)

c. Online quizzes

i. Approximately how long ago did you begin placing quizzes online?

d. Online exams 
i. Approximately how long ago did you begin placing exams online?

e. Learning outcomes

i. Do you track any of your learning outcomes online?

f. Online discussions

i. Approximately how long ago did you begin placing discussions online?

g. Online collaborative projects (e.g., Google Docs, Google Hangouts)

i. Approximately how long ago did you begin using online collaborative projects?

h. Live online class lecture (e.g., Adobe Connect, Google Hangouts)

i. Approximately how long ago did you begin using live online class lectures?

i. Online learning resources used primarily for online instruction (e.g., videos, simulations, websites)

i. Approximately how long ago did you begin using such learning resources?

j. Other (Please describe)

2. Have you reduced the time or frequency you meet in class because you placed a portion of your course online?

i. Yes, I reduced overall class time by at least $50 \%$

ii. Yes, I have reduced overall class time by approximately $25-49 \%$

iii. Yes, I have reduced overall class time by approximately $1-24 \%$

iv. No, I have not reduced the time or frequency I meet in class

\section{What BEST describes your typical reaction to new technologies?}

a. I am constantly adopting multiple new technologies. I adopt well before anyone else, sometimes even before a new technology is publicly available.

b. I actively investigate new technologies and adopt the best ones. I am generally one of the first to adopt a new technology, and my peers adopt based on my recommendation/example.

c. I wait to adopt until I have compelling evidence of the technology's value and recommendations from my peers. I am not among the first to adopt, but I am generally in the first half of those adopting a technology.

d. I am not necessarily opposed to new technologies, but I am cautious and will only adopt when it becomes necessary to do so.

e. I recognize that new technologies have value to my colleagues, but I feel strongly about using traditional resources. I will continue using my current resources, even when pressured to adopt a new technology.

\section{A.3. Identify Factors that Influence Adoption Decision and the Extent of Influence}

Please indicate the level of influence each of the following would have on your decision to place a portion of your course online (e.g., placing quizzes, exams, discussions, lectures, learning resources online):

- $\quad$ Significant influence

- Moderate influence

- $\quad$ Minor influence

- $\quad$ No influence

1. Financial stipends for those who commit to place a portion of their course online 
2. Temporary course load reductions for those who commit to place a portion of their course online

3. The availability of technical support for those placing a portion of their course online

4. The availability of pedagogical support for those placing a portion of their course online (e.g., the ongoing ability to consult with an instructional developer regarding course design/delivery)

5. The availability of one-on-one professional development/training for those placing a portion of their course online

6. The availability of professional development/training presented in a face-to-face group setting for those placing a portion of their course online

7. The availability of online professional development/training for those placing a portion of their course online

8. The availability of evaluation data on the effectiveness of placing a portion of a course online

9. Whether management, departments, or the organization make policy decisions regarding online course materials (e.g., intellectual property rights)

10. Whether your organization's course catalog identifies classes with substantial materials and/or activities online

11. The ability to quickly upload and download media/materials at your workplace

12. Whether your organization identifies policies and guidelines regarding placing course materials online (e.g., administrators publish examples of different ways to appropriately combine face-to-face and online instruction)

13. Whether other staff members share their success with placing a portion of their courses online

14. Whether department leadership encourages placing a portion of your course online

15. Whether institutional administrators encourage placing a portion of your course online

16. Whether the institution's reason for promoting technology integration aligns with your own

\section{A.4. Final Questions}

- What was/would be your reaction to being asked to place a portion of your course online?

- What are the greatest challenges you have experienced or would anticipate in placing a portion of your course online?

- If you have placed a portion of your course online, do you feel the value added to your course(s) outweighed the challenges you experienced? Please explain.

\section{Appendix B. Interview Protocol}

\section{B.1. Introduction}

You took a survey in which you were asked to rate the level of influence a number of factors would have on your decision to place a portion of your course online (e.g., placing quizzes, exams, discussions, lectures, learning resources online). The purpose of this interview is to determine why those factors would influence your decision to the level you indicated. A copy of your survey responses will be available to you during the interview.

\section{B.2. Questions}

1. Why would financial stipends for those who commit to place a portion of their course online influence your opinion to the level you indicated in the survey?

2. Why would temporary course load reductions for those who commit to place a portion of their course online influence your opinion to the level you indicated in the survey? 
3. Why would the availability of technical support for those placing a portion of their course online influence your opinion to the level you indicated in the survey?

4. Why would the availability of pedagogical support for those placing a portion of their course online (e.g., the ongoing ability to consult with an instructional designer regarding course design/delivery) influence your opinion to the level you indicated in the survey?

5. Why would the availability of one-on-one professional development/training for those placing a portion of their course online influence your opinion to the level you indicated in the survey?

6. Why would the availability of professional development/training presented in a face-to-face group setting for those placing a portion of their course online influence your opinion to the level you indicated in the survey?

7. Why would the availability of online professional development/training for those placing a portion of their course online influence your opinion to the level you indicated in the survey?

8. Why would the availability of evaluation data on the effectiveness of placing a portion of a course online influence your opinion to the level you indicated in the survey?

9. Why would it influence your opinion to the level you indicated in the survey if management, departments, or the organization make policy decisions regarding online course materials (e.g., intellectual property rights)?

10. Why would it influence your opinion to the level you indicated in the survey if your organization's course catalog identifies classes with substantial materials and/or activities online?

11. Why would the ability to quickly upload and download media/materials at your workplace influence your opinion to the level you indicated in the survey?

12. Why would it influence your opinion to the level you indicated in the survey if your organization identifies policies and guidelines regarding placing course materials online (e.g., administrators publish examples of different ways to appropriately combine face-to-face and online instruction)?

13. Why would it influence your opinion to the level you indicated in the survey if other staff members share their success with placing a portion of their courses online?

14. Why would it influence your opinion to the level you indicated in the survey if department leadership encourages placing a portion of your course online?

15. Why would it influence your opinion to the level you indicated in the survey if institutional administrators encourage placing a portion of your course online?

16. Why would it influence your opinion to the level you indicated in the survey if the institution's reason for promoting technology integration aligns with your own?

17. Is there anything else that would influence your decision to place a portion of your course online? 